\title{
Phase II study of adjuvant chemotherapy with S1 plus oxaliplatin for Chinese patients with gastric cancer
}

Guoxiu Wang ${ }^{1,2+}$, Jiuda Zhao ${ }^{1,3+}$, Yan Song ${ }^{1}$, Wen Zhang ${ }^{1}$, Yongkun Sun ${ }^{1}$, Aiping Zhou', Jing Huang ${ }^{1}$, Feng Du ${ }^{1,4}$ and Lin Yang ${ }^{1 *}$

\begin{abstract}
Background: S-1 plus oxaliplatin(SOX) has been demonstrated to be effective and well tolerated for patients with metastatic gastric cancer. We conducted this phase II study to evaluate the feasibility of SOX as adjuvant chemotherapy for gastric cancer after curative resection.

Methods: Adjuvant chemotherapy consisted of six to eight cycles of S-1 plus oxaliplatin. Oxaliplatin was administered intravenously at a dose of $130 \mathrm{mg} / \mathrm{m}^{2}$ on day 1 . S-1 was administered orally at a dose of $70 \mathrm{mg} / \mathrm{m}^{2}$ daily from day 1 to 14 of a 3-week cycle. A total of 58 patients were enrolled in this study. The primary end point of the trial was the treatment completion rate for six cycles. Secondary endpoints were safety, 1-year and 3-year of disease free survival (DFS) and overall survival (OS).
\end{abstract}

Results: A total of 58 patients were enrolled and 54 patients have been analysed. The completion rate of six cycles was 72.2\%. Grade 4 toxicities included neutropenia (1.9\%) and thrombocytopenia (3.7\%). Grade 3 toxicities included leukopenia (5.6\%), neutropenia (24.1\%), thrombocytopenia (13.0\%), nausea (7.4\%), vomiting $13.0 \%)$, and diarrhea (13.0\%). There was no grade 3 or higher peripheral sensory neuropathy and treatment-related death. The median follow-up time was 42.4 months. 1-year and 3-year DFS rate were 85.2 and 75.9\%, respectively.1-year and 3-year OS were 98.1 and $85.2 \%$, respectively.

Conclusion: Adjuvant chemotherapy for GC with S-1 plus oxaliplatin is safe and feasible in Chinese patients. The optimal dose of oxaliplatin and optimal cycles of treatment still need to be further investigated.

Trial registration: clinicaltrials.gov identifier NCT01542294. Trial registration date: 03/02/2012.

Keywords: Gastric cancer, S-1, Oxaliplatin, Adjuvant chemotherapy

\section{Background}

Gastric cancer (GC) is the fourth most common malignancy and the second leading cause of cancer related death in the world [1]. Curative treatments for GC remain a challenge with 988,000 new cases and 73,000 deaths each year [2]. In China, GC is the second-leading cause of cancer death for both men and women [3]. Surgical resection is the only curative treatment option for localized

\footnotetext{
*Correspondence: linyang@cicams.ac.cn

${ }^{\dagger}$ Equal contributors

'Department of Medical Oncology, National Cancer Center/Cancer Hospital, Chinese Academy of Medical Sciences and Peking Union Medical College, Beijing 100021, China

Full list of author information is available at the end of the article
}

disease. However, locally advanced (stage II-III) GC often recurs, even after curative resection is performed. Therefore, adjuvant systemic chemotherapy plays a crucial role in improving the prognosis in patient with resectable GC.

$\mathrm{S}-1$ is an oral anticancer agent containing tegafur (FT), 5-chloro-2,4-dihydroxipyridine (CDHP) and potassium oxonate (Oxo) at a molar ratio of 1:0.4:1. It showed approximately $40 \%$ of response rate in phase II trials in patients with advanced or recurrent GC $[4,5]$. Based on the results from the ACTS-GC trial [6, 7], S-1 monotherapy for 1 year was established as the standard postoperative adjuvant chemotherapy for GC in Japan. However, a subgroup analysis of data demonstrated that both disease free survival (DFS) and overall survival

(c) The Author(s). 2018 Open Access This article is distributed under the terms of the Creative Commons Attribution 4.0 International License (http://creativecommons.org/licenses/by/4.0/), which permits unrestricted use, distribution, and reproduction in any medium, provided you give appropriate credit to the original author(s) and the source, provide a link to the Creative Commons license, and indicate if changes were made. The Creative Commons Public Domain Dedication waiver (http://creativecommons.org/publicdomain/zero/1.0/) applies to the data made available in this article, unless otherwise stated. 
(OS) of patients with stage IIIb and IV was not improved. It is urgent to investigate new treatment strategy.

For recurrent or metastatic GC, combined with S-1 and cisplatin (SP) showed improved progression free survival (PFS) and OS compared with S-1 alone [8]. But in adjuvant setting, SP was demonstrated too toxic as a post-gastrectomy treatment $[9,10]$. For patients with $\mathrm{GC}$, oxaliplatin was more tolerable than cisplatin, without compromising the antitumor effect, which was evidenced by the data from one randomized clinical trial demonstrating a favourable safety profile and equivalent benefit in patients who received S-1 plus oxaliplatin versus those with S-1 and cisplatin [11].

In China, SOX regimen with $130 \mathrm{mg} / \mathrm{m}^{2}$ oxaliplatin was commonly used. Our data showed that the SOX regimen with $130 \mathrm{mg} / \mathrm{m}^{2}$ oxaliplatin was a promising regimen as the first-line chemotherapy in patients with advanced GC [12]. As adjuvant chemotherapy for postoperative GC, when combined with $130 \mathrm{mg} / \mathrm{m}^{2}$ oxaliplatin every 3 weeks, $70 \mathrm{mg} / \mathrm{m}^{2} /$ day S- 1 for 2 weeks was the optimal dose in our phase I study [13, 14]. We conducted this phase II study to further evaluate the tolerability and safety of SOX as adjuvant therapy after curative resection in Chinese patients with GC.

\section{Methods}

\section{Study design and patients}

This is a single-arm, prospective, phase 2 study conducted at Cancer Institute and Hospital of Chinese Academy of Medical Sciences (Beijing, China) in accordance with the Helsinki Declaration and the good clinical practice guidelines. The study protocol was approved by the ethics committee of Cancer Hospital, Chinese Academy of Medical Sciences and Peking Union Medical College (approval number 11-41/476). All patients provided written informed consent before starting of the study. This study was registered on clinicaltrials.gov on March 2, 2012 (Identifier: NCT01542294).

The inclusion criteria were as follows: histologically confirmed stage II-III gastric adenocarcinoma (according to the 7th edition of the American Joint Committee on Cancer tumor-node-metastasis system); R0 surgery with D2 or more extensive lymphadenectomy; can start chemotherapy within 6 weeks after surgery; no prior chemotherapy or radiotherapy; sufficient oral intake; age distribution of 20 to70 years old; an Eastern Cooperative Oncology Group (ECOG) performance status of 0-1; adequate bone marrow, renal and liver function, including an absolute granulocyte counts of $>1500 / \mathrm{L}$; a platelet counts of $>100,000 / \mathrm{L}$; a hemoglobin level of $>90 \mathrm{~g} / \mathrm{L}$; a serum bilirubin level of less than the upper limit of normal (ULN); a normal creatinine level; an alanine transaminase and aspartate transaminase level of $<1.5 \times \mathrm{ULN}$; electrocardiogram was normal. Patients with ascites or evidence of peritoneal, hepatic or distant metastases were excluded from this study. Patients were also excluded if they had mental abnormalities, severe comorbid conditions, severe drug hypersensitivity or peripheral sensory neuropathy.

\section{Treatment and assessment}

Chemotherapy consisted of six to eight cycles of S-1 plus oxaliplatin. All treatment cycles were administered every 3 weeks. S-1 was administered orally twice daily at a dose of $70 \mathrm{mg} / \mathrm{m}^{2} /$ day from day 1 to 14 . Oxaliplatin was infused intravenously for $2 \mathrm{~h}$ on day 1 at a dose of $130 \mathrm{mg} / \mathrm{m}^{2}$. Before infusion of oxaliplatin, antiemetics (e.g., a 5-hydroxytryptamine3 receptor antagonist and dexamethasone) were administered prophylactically to prevent nausea and vomiting. If patients developed grade 4 haematological toxicities, or grade 3-4 diarrhea, laryngeal mucositis, peripheral sensory neuropathy and palmer-planter erythrodysestheia syndrome, the doses of both oxaliplatin and S-1 were reduced by $20 \%$. The dose of oxaliplatin was reduced if the platelet count was less than $75,000 / \mathrm{mm}^{3}$ on day 23 with delayed initiation of the next treatment cycle or if grade 2 peripheral sensory neuropathy was noted on the first day of the next cycle. S-1 and oxaliplatin could be reduced twice, but treatment was discontinued if subsequent reduction was indicated. In the cases of oxaliplatin-related peripheral sensory neuropathy, S-1 could be continued as monotherapy. But oxaliplatin monotherapy was not allowed if S-1 was discontinued.

During the study, complete blood count and blood chemistry studies were performed before initiation of each cycle. Computed tomography or magnetic resonance image were performed as baseline before chemotherapy. Then, the presence or absence of disease recurrence was evaluated every 3 months for 2 years, then every 6 months for 3 years. Adverse events were evaluated using the National Cancer Institute-Common Toxicity Criteria version 4.0.

\section{Statistical analysis}

The primary end point was the treatment completion rate for six cycles of SOX therapy. Treatment completion was defined as the percentage of patients who completed six cycles of SOX therapy and included patients who continued with S-1 monotherapy after discontinuation of oxaliplatin treatment. The point estimate and 95\% confidence interval (CI) were calculated. Secondary endpoints were safety, 1-year and 3-year of DFS and OS.

The required sample size was calculated according to our previous work and a phase 3 trial. Our phase 2 trial of SOX as a fist-line chemotherapy for patients with advanced $\mathrm{GC}$ shown that the median number of cycles for the SOX regimen was five (range, 2-8). In addition, the actual treatment completion rates of adjuvant treatmen 
as capecitabine plus oxaliplatin for GC in the CLASSIC study was $67 \%$. Therefore, the SOX regimen was considered as feasible if the point estimate of the treatment completion rate was not lower than $70 \%$ in this study. Considering the expected treatment completion rate was $70.0 \%$ and the range of the accurate $95 \% \mathrm{CI}$ of the point estimate for the treatment completion rate was $26 \%$ or less, the required sample size was estimated to be 53 patients. Thus, the target enrollment was 58 patients, in order to make accommodations for $10 \%$ dropout rate.

The treatment completion rate was defined as the percentage of patients who completed all the six cycles of SOX therapy, and included patients who continued with S-1 monotherapy after discontinuation of oxaliplatin therapy. A safety analysis was conducted in patients who received at least one dose of S-1 or oxaliplatin. The treatment completion rate and the ratio of delivered dose to the planned dosage administration were analyzed for the patients who met the inclusion criteria. Patient characteristics, feasibility, adverse events, DFS and OS were analysed. DFS was defined as the time from the date of surgery to the date of documented recurrence or death from any cause, or last follow-up, whichever came first. OS was defined as the time from the date of surgery to the date of death from any cause, or last follow-up. Survival curves were estimated using the Kaplan-Meier method. All analyses were carried out using an SPSS 23.0 software package (SPSS Inc., Chicago, IL, USA).

\section{Results}

\section{Patient characteristics}

Between May 2011 and April 2014, 58 patients were enrolled to the study. Among them, 3 did not receive allocated intervention, 1 did not meet inclusion criteria. 54 patients were included in the safety analysis and the full analysis set. The patient characteristics are summarized in Table 1. There were 37 males and 17 females. The median age was 55 years (range, $30-70$ years). The body surface area (BSA) ranged from 1.35 to $2.06 \mathrm{~m}^{2}$. All patients exhibited a good performance status (ECOG $0-1)$. Total gastrectomy and partial gastrectomy were performed in $8(14.8 \%)$ and 47 (85.2\%) patients, respectively.11 (20.4\%) had stage IIA disease, 11 (20.4\%) had stage IIB disease, 12 (22.2\%) had stage IIIA, 12 (22. $2 \%)$ had stage IIIB, $8(14.8 \%)$ had stage IIIC disease.

\section{Compliance}

Thirty-nine patients completed six cycles of treatment, and the treatment completion rate was $72.2 \%$ (95\% CI 60.25-84.15\%), and 26 patients (48.1\%) completed eight cycles of treatment (Tables 2 and 3), which was consistent with our prior study [11]. The treatment completion
Table 1 Patient characteristics $n=54$

\begin{tabular}{|c|c|c|c|c|c|}
\hline \multicolumn{6}{|l|}{ Characteristic } \\
\hline \multicolumn{3}{|l|}{ Age(years) } & \multicolumn{3}{|c|}{ Type of gastrectomy } \\
\hline & median & 55 & & total & 8 \\
\hline & range & $30-71$ & & partial & 45 \\
\hline \multirow[t]{3}{*}{ Gender } & & & & $\begin{array}{l}\text { combined } \\
\text { resection }\end{array}$ & 2 \\
\hline & male & 37 & Tumor $\mathrm{F}$ & osition & \\
\hline & female & 17 & & cardia & 8 \\
\hline \multirow[t]{3}{*}{ PS(ECOG) } & & & & fundus ventriculi & 10 \\
\hline & 0 & 14 & & corpus ventriculi & 25 \\
\hline & 1 & 40 & & autrum pyloricum & 11 \\
\hline \multirow[t]{3}{*}{$\mathrm{BSA}\left(\mathrm{m}^{2}\right)$} & & & T stage & & \\
\hline & median & 1.7 & & pT1 & 4 \\
\hline & range & $\begin{array}{l}1.35- \\
2.06\end{array}$ & & pT2 & 6 \\
\hline \multicolumn{2}{|c|}{ Pathological type } & & & pT3 & 24 \\
\hline & intestinal & 14 & & pT4 & 20 \\
\hline & diffuse & 15 & $\begin{array}{l}\mathrm{N} \\
\text { stage }\end{array}$ & & \\
\hline & mixed & 17 & & pNO & 10 \\
\hline & unknow & 8 & & $\mathrm{pN1}$ & 14 \\
\hline \multirow[t]{4}{*}{ Differentiation } & & & & pN2 & 16 \\
\hline & moderately & 7 & & pN3a & 11 \\
\hline & low & 45 & & $\mathrm{pN} 3 \mathrm{~b}$ & 3 \\
\hline & unknown & 2 & TNM sta & & \\
\hline \multicolumn{3}{|c|}{ Vessel tumor emboli } & & la & 1 \\
\hline & no & 29 & & $\mathrm{lb}$ & 2 \\
\hline & yes & 24 & & Ila & 8 \\
\hline & unknown & 1 & & $11 \mathrm{~b}$ & 11 \\
\hline \multirow[t]{4}{*}{ Nerve invasion } & & & & Illa & 12 \\
\hline & no & 28 & & $\| l l b$ & 12 \\
\hline & yes & 25 & & IIIC & 7 \\
\hline & unknown & 1 & & $\mathrm{IV}^{\mathrm{a}}$ & 1 \\
\hline
\end{tabular}

BSA body surface area, ECOG PS Eastern Cooperative Oncology Group performance status

aperitoneal metastasis(P1)

rate was $67.57 \%$ for male and $82.35 \%$ for female, $77.78 \%$ for patients who underwent total gastrectomy and $71.11 \%$ $\%$ for those who underwent partial gastrectomy, $74.07 \%$ for $<55$ years-old patients, $69.57 \%$ for $55-65$ years-old patients and $75.00 \%$ for 65 years or older.

Fifteen patients (27.8\%) could not complete the six cycles of treatment and the reason for discontinuation were as follows: seven patients discontinued therapy because of adverse events (AEs) (thrombocytopenia in 5 patients, vomiting in 2 patients,); six patients withdrew informed consent; t wo patients were detected retroperitoneal lymph node metastasis. 
Table 2 Chemotherapy completion rate $n=54$

\begin{tabular}{lllll}
\hline No. of cysles & \multicolumn{2}{l}{ Complete chemotherapy } & \multicolumn{2}{l}{ Complete SOX } \\
\hline & No. (\%) & $95 \% \mathrm{Cl}$ & No. $(\%)$ & $95 \% \mathrm{Cl}$ \\
1 & $54(100)$ & $1.00,1.00$ & $54(100)$ & $1.00,1.00$ \\
2 & $51(94.4)$ & $0.88,1.01$ & $51(94.4)$ & $0.88,1.01$ \\
3 & $47(87.0)$ & $0.78,0.96$ & $45(83.3)$ & $0.73,0.93$ \\
4 & $45(83.3)$ & $0.73,0.93$ & $40(74.1)$ & $0.62,0.86$ \\
5 & $44(81.5)$ & $0.71,0.92$ & $37(68.5)$ & $0.56,0.81$ \\
6 & $39(72.2)$ & $0.60,0.84$ & $31(57.4)$ & $0.44,0.71$ \\
7 & $27(50)$ & $0.37,0.63$ & $13(24.1)$ & $0.13,0.36$ \\
8 & $26(48.1)$ & $0.35,0.61$ & $12(22.2)$ & $0.11,0.33$ \\
\hline
\end{tabular}

Nine patients (16.7\%) experienced one level of S-1 dose reduction, and no patient required two level of S-1 dose reduction. Twenty-one patients (38.9\%) experienced one level of oxaliplatin dose reduction, and 1 patient $(1.9 \%)$ required two level of dose reduction. Fortyseven $(87 \%)$ patients experienced treatment delay of initiation subsequent cycle. The main reason of dose reduction and treatment-delay were AEs including thrombocytopenia, neutropenia vomiting and peripheral sensory neuropathy.

The most common reasons for discontinuation of oxaliplatin by investigators decision were thrombocytopenia and peripheral sensory neuropathy. The median relative dose intensities were $98.6 \%$ for S-1 and $96.5 \%$ for oxaliplatin.

\section{Safety}

All of the 54 patients were assessable for AEs (Table 4). Grade 3 AEs occurred in 36 (66.7\%) patients and grade 4 AEs occurred in 3(5.6\%) patients. There were no treatment-related deaths. The most common hematological toxicities of all grades include leucopenia $(75.9 \%)$ and neutropenia (72.2\%) and thrombocytopenia (61.1\%). Grade 3/4 hematological toxicities were leucopenia (5.6\%), neutropenia (26\%) and thrombocytopenia (16.7\%). Grade 4 neutropenia and thrombocytopenia occurred in $1(1.9 \%)$ and 2(3.7\%) patients, respectively. Among nonhematological toxicity of all grades, nausea was the most frequent $(77.8 \%)$ followed by peripheral sensory neuropathy (61.1\%), asthenia (53.7\%) and vomiting (38.9\%). Grade 3 non-hematological toxicity included vomiting (13.0\%), nausea $(7.4 \%)$, diarrhea (1.9\%). However, there were no grade 4 non-hematological adverse reactions.

\section{DFS and OS}

The median follow-up time was 42.4 months (range, 37. 2-47.6 months). There were 13 patients recurred. The 3-year DFS were $75.9 \%$. The 1-year DFS were $85.2 \%$. There were 8 patients died. The the 3 -year OS were 85 . $2 \%$, and 1 -year OS were $98.1 \%$. (Figs. 1 and 2).

\section{Discussion}

To our knowledge this is the first report on the toxicity and safety analysis of oxaliplatin plus S-1 (SOX) treatment for Chinese patients with stage II/III gastric cancer

Table 3 Tolerability of subgroups

\begin{tabular}{|c|c|c|c|c|c|c|c|}
\hline & \multirow[t]{3}{*}{$\mathrm{n}$} & \multicolumn{2}{|c|}{ Treatment completion rate (\%) } & \multicolumn{4}{|c|}{ Relative dose intensities(\%) } \\
\hline & & \multirow[t]{2}{*}{6 cycle $(\%)$} & \multirow[t]{2}{*}{8 cycle (\%) } & \multicolumn{2}{|l|}{ mean } & \multicolumn{2}{|l|}{ median } \\
\hline & & & & S-1 (\%) & Oxaliplatin (\%) & $\mathrm{S}-1(\%)$ & Oxaliplatin (\%) \\
\hline \multicolumn{8}{|c|}{ Age(years) } \\
\hline$<55$ & 27 & $20(74.07)$ & $15(55.56)$ & 68.74(98.20) & $124.11(95.47)$ & $68.00(97.14)$ & 127.00(97.69) \\
\hline $55 \sim 65$ & 23 & $16(69.57)$ & $9(39.13)$ & 69.60(99.43) & 123.74(95.18) & $70.00(100.00)$ & $125.00(96.15)$ \\
\hline$\geq 65$ & 4 & $3(75.00)$ & $2(50.00)$ & $69.75(99.64)$ & $116.25(89.42)$ & $70.00(100.00)$ & $116.50(89.62)$ \\
\hline \multicolumn{8}{|l|}{ Gender } \\
\hline Male & 37 & $25(67.57)$ & $17(45.95)$ & $69.38(99.11)$ & $122.32(94.10)$ & $70.00(100.00)$ & $124.00(95.38)$ \\
\hline Female & 17 & $14(82.35)$ & $9(52.94)$ & $68.77(98.24)$ & $125.65(96.65)$ & 68.00(97.14) & $129.00(99.23)$ \\
\hline \multicolumn{8}{|c|}{$\mathrm{PS}(\mathrm{ECOG})$} \\
\hline 0 & 14 & $10(71.43)$ & $6(42.86)$ & $68.64(98.06)$ & 125.29 (96.37) & $68.50(97.86)$ & $127.50(98.08)$ \\
\hline 1 & 40 & $29(72.50)$ & $20(50.00)$ & $69.38(99.11)$ & $122.70(94.38)$ & $70.00(100.00)$ & $123.00(94.62)$ \\
\hline \multicolumn{8}{|l|}{ BSA } \\
\hline$<1.7$ & 26 & $22(84.62)$ & $13(50.00)$ & $70.85(101.21)$ & 123.96 (95.36) & 71.00 (101.43) & $125.00(96.15)$ \\
\hline$\geq 1.7$ & 28 & $17(60.71)$ & $13(46.43)$ & $67.64(96.63)$ & $122.82(94.48)$ & 68.00(97.14) & $126.00(96.92)$ \\
\hline \multicolumn{8}{|c|}{ Type of gastrectomy } \\
\hline Total & 9 & 7 (77.78) & $4(44.44)$ & $70.33(100.48)$ & $121.22(93.25)$ & 71.00 (101.43) & $119.00(91.54)$ \\
\hline Partial & 45 & 32 (71.11) & $22(48.89)$ & $68.96(98.51)$ & 123.80 (95.23) & 68.00(97.14) & $126.00(96.92)$ \\
\hline
\end{tabular}


Table 4 Drug-related adverse events $n=54$

\begin{tabular}{|c|c|c|c|c|c|}
\hline \multicolumn{6}{|l|}{ Adverse events } \\
\hline & Grade $1(\%)$ & Grade $2(\%)$ & Grade $3(\%)$ & Grade $4(\%)$ & All grades (\%) \\
\hline Leukopenia & 16 (29.6) & $22(40.7)$ & $3(5.6)$ & 0 & $41(75.9)$ \\
\hline Neutropenia & $11(20.4)$ & $14(25.9)$ & $13(24.1)$ & $1(1.9)$ & $39(72.2)$ \\
\hline Anemia & $17(31.5)$ & $8(14.8)$ & 0 & 0 & $25(46.3)$ \\
\hline Thrombocytopenia & $13(24.1)$ & $11(20.4)$ & $7(13.0)$ & $2(3.7)$ & $33(61.1)$ \\
\hline Febrile neutropenia & - & - & $1(1.9)$ & 0 & $1(1.9)$ \\
\hline Skin hyperpigmentation & $25(46.3)$ & 0 & - & - & $25(46.3)$ \\
\hline Malaise & $29(53.7)$ & 0 & - & - & $29(53.7)$ \\
\hline Nausea & $25(46.3)$ & $13(24.1)$ & $4(7.4)$ & - & $42(77.8)$ \\
\hline Vomiting & $7(13.0)$ & $7(13.0)$ & $7(13.0)$ & 0 & $21(38.9)$ \\
\hline Laryngeal mucositis & $2(3.7)$ & 0 & 0 & 0 & $2(3.7)$ \\
\hline Diarrhea & $2(3.7)$ & $1(1.9)$ & $1(1.9)$ & 0 & $4(7.4)$ \\
\hline Peripheral sensory neuropathy & $32(59.3)$ & $1(1.9)$ & 0 & 0 & $33(61.1)$ \\
\hline Palmer-planter erythrodysestheia syndrome & $1(1.9)$ & 0 & 0 & - & $1(1.9)$ \\
\hline Alanine aminotransferase increased & $9(16.7)$ & $3(5.6)$ & 0 & 0 & $12(22.2)$ \\
\hline
\end{tabular}

who had received curative D2 gastrectomy. In the present study, the six cycles chemotherapy completion rate was $72.2 \%$ (95\% CI 60.25-84.15\%), similar with our previous work and other regimens reported in different trials $[6,13,15]$. The safety profile of SOX observed in the present study were comparable as previously reported in patients who received SOX regimen for advanced gastric cancer $[11,16]$. The most frequent (incidence rate $10 \%$ or more) grade $3 / 4$ AEs were neutropenia (26\%), thrombocytopenia (16.7\%) and vomiting (13.0\%).

The main reason for discontinuation of chemotherapy is thrombocytopenia which we think mainly due to oxaliplatin. Yamada Y et al. [11] recently reported a phase III randomized trial conducted in Japan comparing SOX with SP showed that SOX is as effective as SP for AGC with favorable safety profile. The dose of oxaliplatin they used is $100 \mathrm{mg} / \mathrm{m}^{2}$ every 3 weeks. Grade 3/4

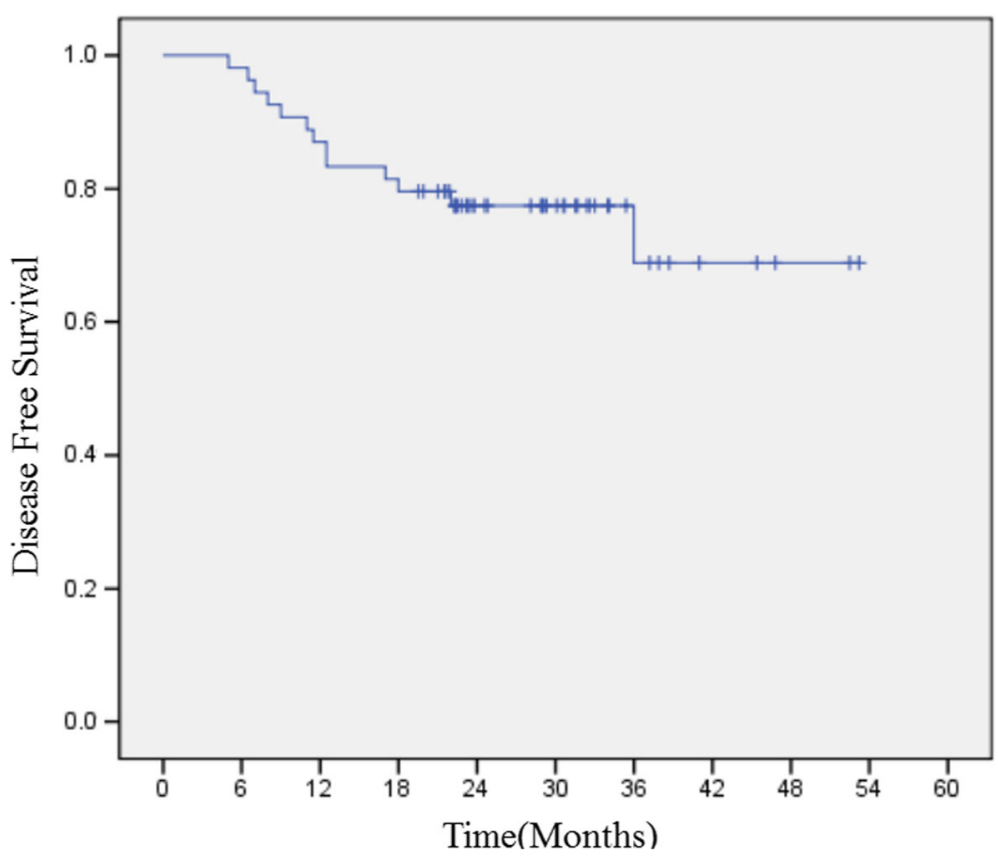

Fig. 1 Disease-free survival curve for patients treated with adjuvant S1 plus oxaliplatin chemotherapy 


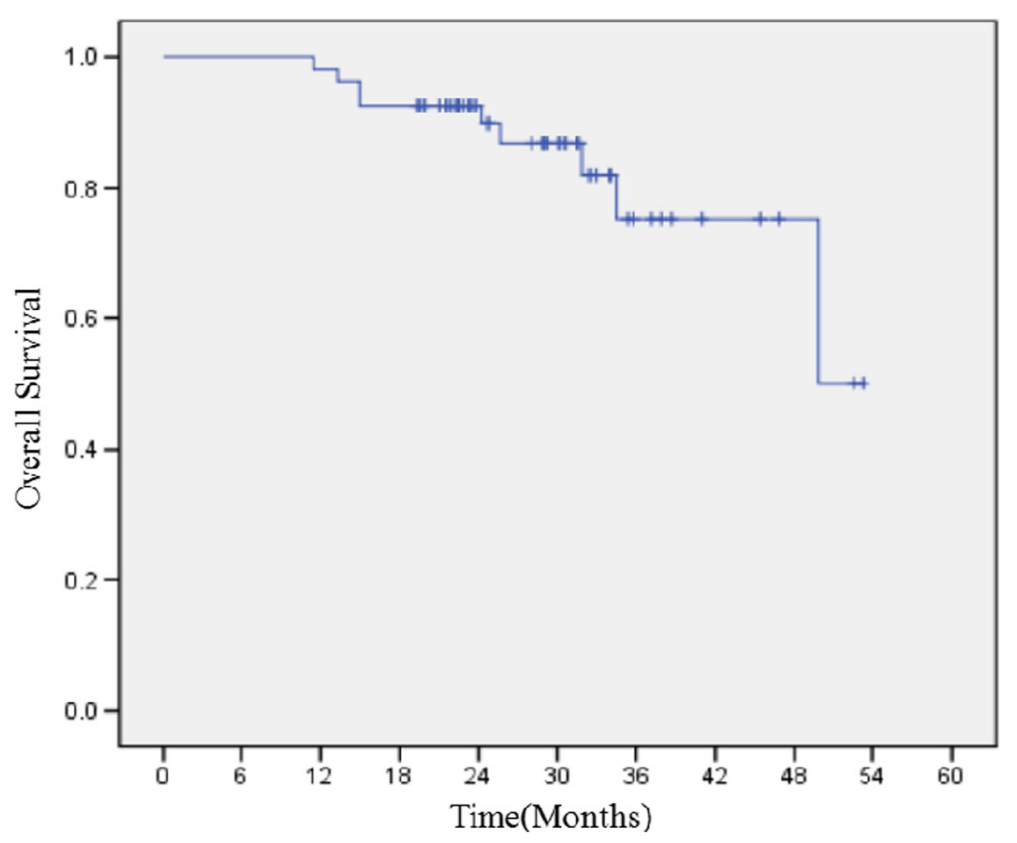

Fig. 2 Overall survival curve for patients treated with adjuvant S1 plus oxaliplatin chemotherapy

thrombocytopenia is only $10.1 \%$, the same as SP $(10.3 \%)$. So, reduction of the dosage of oxaliplatin is one way of reducing risk of grade $3 / 4$ thrombocytopenia. Shitara K et al. [17] conducted a phase II trial to investigate the tolerability and safety of 8 cycles of SOX (oxaliplatin $100 \mathrm{mg} / \mathrm{m}^{2}$ ) as adjuvant chemotherapy for stage III gastric cancer. No grade 4 or higher events occurred. Grade 3 thrombocytopenia in only $4.8 \%$. The completion rate of treatment was $74.2 \% .41 .9$ and $61.7 \%$ patients required dose reduction of S-1 and oxaliplatin, respectively, and $82.3 \%$ patients required chemotherapy administration to be delayed mainly because of AEs. A study has conveyed that S-1 monotherapy as the first cycle, followed by 3 cycles of S-1 plus cisplatin for gastric cancer adjuvant chemotherapy is feasible and tolerable [10]. Moreover, considering chemotherapy was administrated soon after operation, the patients in this study also treated as S- 1 in the first cycle, and SOX regimen after the first cycle. The authors think that such a design may contribute to the favorable treatment completion rate. However, the efficacy of such treatment was not estimated in this study.

In our study, 16.7 and $38.9 \%$ patients required dose reduction of S-1 and oxaliplatin, respectively, mainly because of AEs including thrombocytopenia, neutropenia vomiting and peripheral sensory neuropathy. The dose reduction rate is lower than the Japanese study [17]. The reason may be that the dose of $\mathrm{S}-170 \mathrm{mg} / \mathrm{m} 2$ we recommend is more appropriate for Chinese patients when combined with oxaliplatin $130 \mathrm{mg} / \mathrm{m} 2.87 \%$ patients required chemotherapy administration to be delayed, which is similar to the Japanese study [17]. In the ARTIST trial [18] comparing postoperative treatment with capecitabine plus cisplatin (XP) versus XP plus radiotherapy with capecitabine (XP/XRT/XP), treatment was completed as planned by $75.4 \%$ of patients (172 of 228) in the XP arm and the estimated 3-year DFS rates were $74.2 \%$ in the XP arm. The 3 year DFS and OS was 72.2 and $80.1 \%$ [6] for S-1 monotherapy for 1 year and 74 and $83 \%$ [15] for capecitabine plus oxaliplatin (XELOX) treatment for 6 months, respectively. In our study, 72.2\% (95\%CI $60-84 \%)$ of patients received at least six cycles of treatment and the 3-year DFS were $75.9 \%$ that is close to other studies. $[15,17,19]$.

Although there occurred dose reduction, treatment delay and treatment discontinuation, there was not significant difference in the treatment completion rate and relative dose intensities for patients in gender, age, performance status, body surface acre and type of gastrectomy.

\section{Conclusions}

In conclusion, adjuvant chemotherapy for GC with S-1 plus Oxaliplatin is safe and feasible in Chinese patients. The optimal dose of Oxaliplatin and optimal cycles of treatment still need to be further investigated.

\section{Abbreviations}

AEs: Adverse events; BSA: Body surface area; Cl: Confidence interval; DFS: Disease free survival; ECOG: Eastern Cooperative Oncology Group; GC: Gastric cancer; OS: Overall survival; DFS: Disease free survival; SOX: S-1 plus oxaliplatin; SP: S-1 and cisplatin; ULN: Upper limit of normal; XELOX: Capecitabine plus oxaliplatin; XP: Capecitabine plus cisplatin 


\section{Acknowledgements}

We thank all the staff of the department of Medical Oncology, Cancer Hospital \& Institute, Chinese Academy of Medical Sciences \& Peking Union Medical College who supported our study. We also thank all study participants and research staff who participated in this work.

This study was presented in part at ESMO 18th World Congress on Gastrointestinal Cancer, Barcelona, Spain, 29 June-2 July 2016. Annals of Oncology 27 (Supplement 2): ii1-ii85, 2016. doi: https://doi.org/10.1093/annonc/mdw199.78.

\section{Availability of data and materials}

Our data can not be made publicly available for ethical reasons. Data are from the present study whose authors may be contacted at linyang@cicams.ac.cn or Department of Medical Oncology, Cancer Hospital, Chinese Academy of Medical Sciences and Peking Union Medical College, Beijing, China.

\section{Authors' contributions}

GW and JZ contributed equally to this work. GW analysed and interpreted data, technical and material support, drafted the manu script and supervised the study. JZ made acquisition of data, analysed and interpreted the data and performed statistical analysis. YSo, WZ, JH and AZ participated in studies selection and data extraction and provided statistical expertise. YSu and FD interpreted the data and material support. LY conceived of the study, participated in its design, analysed and interpreted the data. All authors read and approved the final manuscript.

\section{Ethics approval and consent to participate}

The Ethics Committee at Cancer Hospital, Chinese Academy of Medical Sciences and Peking Union Medical College approved the study in accordance with the Declaration of Helsinki. All individuals gave written informed consent for participation in the study.

\section{Competing interests}

The authors declare that they have no competing interests.

\section{Publisher's Note}

Springer Nature remains neutral with regard to jurisdictional claims in published maps and institutional affiliations.

\section{Author details}

'Department of Medical Oncology, National Cancer Center/Cancer Hospital, Chinese Academy of Medical Sciences and Peking Union Medical College, Beijing 100021, China. ${ }^{2}$ Department of Medical Oncology, Yangquan No.1 People's Hospital, Shanxi 045000, China. ${ }^{3}$ Affiliated Hospital of Qinghai University, Affiliated Cancer Hospital of Qinghai University, Xining 810000, China. ${ }^{4}$ The VIPII Gastrointestinal Cancer Division of Medical Department, Peking University Cancer Hospital and Institute, Beijing 100142, China.

Received: 21 January 2018 Accepted: 3 May 2018

Published online: 09 May 2018

\section{References}

1. Elimova E, Shiozaki H, Wadhwa R, Sudo K, Chen Q, Estrella JS, Blum MA, Badgwell B, Das P, Song S, Ajani JA. Medical management of gastric cancer: a 2014 update. World J Gastroenterol. 2014;20(38):13637-47.

2. Merrett ND. Multimodality treatment of potentially curative gastric cancer: geographical variations and future prospects. World I Gastroenterol. 2014; 20(36):12892-9.

3. Chen W, Zheng R, Baade PD, Zhang S, Zeng H, Bray F, Jemal A, Yu XQ, He J. Cancer statistics in China, 2015. CA Cancer J Clin. 2016;66(2):115-32.

4. Tsukuda M, Kida A, Fujii M, Kono N, Yoshihara T, Hasegawa Y, Sugita M. Randomized scheduling feasibility study of S-1 for adjuvant chemotherapy in advanced head and neck cancer. Br J Cancer. 2005;93(8):884-9.

5. Koizumi W, Kurihara M, Nakano S, Hasegawa K. Phase II study of S-1, a novel oral derivative of 5 -fluorouracil, in advanced gastric cancer. For the S-1 cooperative gastric Cancer study group. Oncology. 2000;58(3):191-7.

6. Sasako M, Sakuramoto S, Katai H, Kinoshita T, Furukawa H, Yamaguchi T, Nashimoto A, Fujii M, Nakajima T, Ohashi Y. Five-year outcomes of a randomized phase III trial comparing adjuvant chemotherapy with S-1 versus surgery alone in stage II or III gastric cancer. J Clin Oncol. 2011;29(33): 4387-93.
7. Sakuramoto S, Sasako M, Yamaguchi T, Kinoshita T, Fujii M, Nashimoto A, Furukawa H, Nakajima T, Ohashi Y, Imamura H, Higashino M, Yamamura Y, Kurita A, Arai K. Adjuvant chemotherapy for gastric cancer with S-1, an oral fluoropyrimidine. N Engl J Med. 2007;357(18):1810-20.

8. Koizumi W, Narahara H, Hara T, Takagane A, Akiya T, Takagi M, Miyashita K, Nishizaki T, Kobayashi O, Takiyama W, Toh Y, Nagaie T, Takagi S, Yamamura Y, Yanaoka K, Orita H, Takeuchi M. S-1 plus cisplatin versus S-1 alone for first-line treatment of advanced gastric cancer (SPIRITS trial): a phase III trial. Lancet Oncol. 2008;9(3):215-21.

9. Kodera Y, Ishiyama A, Yoshikawa T, Kinoshita T, Ito S, Yokoyama H, Mochizuki Y, Ito H, Tsuburaya A, Sakamoto J, Nakao A: A feasibility study of postoperative chemotherapy with S-1 and cisplatin (CDDP) for gastric carcinoma (CCOG0703). Gastric Cancer 2010,13(3):197-203.

10. Takahari D, Hamaguchi T, Yoshimura K, Katai H, Ito S, Fuse N, Kinoshita T, Yasui H, Terashima M, Goto M, Tanigawa N, Shirao K, Sano T, Sasako M. Feasibility study of adjuvant chemotherapy with S-1 plus cisplatin for gastric cancer. Cancer Chemother Pharmacol. 2011;67(6):1423-8.

11. Yamada Y, Higuchi K, Nishikawa K, Gotoh M, Fuse N, Sugimoto N, Nishina T, Amagai K, Chin K, Niwa Y, Tsuji A, Imamura H, Tsuda M, Yasui H, Fujii H, Yamaguchi K, Yasui H, Hironaka S, Shimada K, Miwa H, Hamada C, Hyodo I. Phase III study comparing oxaliplatin plus S-1 with cisplatin plus S-1 in chemotherapy-naïve patients with advanced gastric cancer. Ann Oncol. 2015;26(1):141-8.

12. Yang L, Song Y, Zhou AP, Qin Q, Chi Y, Huang J, Wang JW. A phase II trial of oxaliplatin plus S-1 as a first-line chemotherapy for patients with advanced gastric cancer. Chin Med J. 2013;126(18):3470-4.

13. Yang L, Yang Y, Qin Q, Zhou A, Zhao J, Wang J, Shu C, Yuan X. Hu S: dosefinding study on adjuvant chemotherapy with S-1 plus oxaliplatin for gastric cancer. Mol Clin Oncol. 2014;2(1):93-8.

14. Yang L, Yang Y, Qin Q, Zhou A, Zhao J, Wang J, Shu C, Yuan X, Hu S, Evaluation of the optimal dosage of S-1 in adjuvant SOX chemotherapy for gastric cancer. Oncol Lett. 2015;9(3):1451-7.

15. Bang YJ, Kim YW, Yang HK, Chung HC, Park YK, Lee KH, Lee KW, Kim YH, Noh SI, Cho JY, Mok YJ, Kim YH, Ji J, Yeh TS, Button P, Sirzén F, Noh SH. Adjuvant capecitabine and oxaliplatin for gastric cancer after D2 gastrectomy (CLASSIC): a phase 3 open-label, randomised controlled trial. Lancet. 2012;379(9813):315-21.

16. Kim GM, Jeung HC, Rha SY, Kim HS, Jung I, Nam BH, Lee KH, Chung HC. A randomized phase II trial of S-1-oxaliplatin versus capecitabine-oxaliplatin in advanced gastric cancer. Eur J Cancer. 2012;48(4):518-26.

17. Shitara K, Chin K, Yoshikawa T, Katai H, Terashima M, Ito S, Hirao M, Yoshida K, Oki E, Sasako M, Emi Y, Tsujinaka T. Phase II study of adjuvant chemotherapy of S-1 plus oxaliplatin for patients with stage III gastric cancer after D2 gastrectomy. Gastric Cancer. 2017;20(1):175-81.

18. Lee J, Lim DH, Kim S, Park SH, Park JO, Park YS, Lim HY, Choi MG, Sohn TS, Noh JH, Bae JM, Ahn YC, Sohn I, Jung SH, Park CK, Kim KM, Kang WK. Phase III trial comparing capecitabine plus cisplatin versus capecitabine plus cisplatin with concurrent capecitabine radiotherapy in completely resected gastric cancer with D2 lymph node dissection: the ARTIST trial. J Clin Oncol. 2012;30(3):268-73.

19. Kang BW, Kim JG, Chae YS, Lee YJ, Lee SJ, Moon JH, Sohn SK, Jung MK, Jeon SW, Jang YJ, Seo J, Lee YH, Kwon O, Chung HY, Yu W. Pilot study of adjuvant chemotherapy with 3-week combination of S-1 and cisplatin for patients with stage II-IV (M0) gastric cancer. Investig New Drugs. 2012;30(4): 1671-5. ence

\section{Ready to submit your research? Choose BMC and benefit from:}

- fast, convenient online submission

- thorough peer review by experienced researchers in your field

- rapid publication on acceptance

- support for research data, including large and complex data types

- gold Open Access which fosters wider collaboration and increased citations

- maximum visibility for your research: over $100 \mathrm{M}$ website views per year

At BMC, research is always in progress.

Learn more biomedcentral.com/submissions 